\title{
O Uso das Tecnologias Digitais Acopladas aos Projetos de Conhecimento para Promover à Criatividade em Matemática
}

\author{
Antonio Neres Oliveira ${ }^{1}$, Magda Bercht ${ }^{2}$, Marcus Vinícius de Azevedo Basso ${ }^{2}$, \\ Allison Costa do Nascimento ${ }^{1}$ \\ ${ }^{1}$ Universidade Federal do Maranhão (UFMA), Imperatriz - MA - Brasil \\ ${ }^{2}$ Universidade Federal do Rio Grande do Sul (UFRGS), Porto Alegre - RS - Brasil \\ aneresoliveira@gmail.com, berchteinf.ufrgs.br, basso.marcus@gmail.com, \\ allison nascimento@hotmail.com
}

\begin{abstract}
The new generations are closely linked and involved the technological innovations, however there is a gap between information and education still to be overcome. This article describes a teaching experience coupled with a knowledge of the project, to promote creativity in mathematics aligned methodology problem solving. The study made use of participatory quantum-qualitative research, which gathered a sample of 36 students from the ninth grade of elementary school of a municipal school in the city of Imperatriz-MA. The results show the potential of digital technologies when mediated knowledge projects in the development of creativity in Mathematics.
\end{abstract}

Resumo. As novas gerações estão intimamente ligadas e implicadas pelas novidades tecnológicas, entretanto existe um abismo entre informática e a educação ainda a ser superado. Este artigo descreve uma experiência didática acoplada a um projeto de conhecimento, no sentido de promover a criatividade em matemática alinhada à metodologia de resolução de problemas. $O$ estudo fez uso da pesquisa quanto-qualitativa participativa, que congregou uma amostra de 36 alunos do nono ano do ensino fundamental de uma escola municipal da cidade de Imperatriz-MA. Os resultados mostram o potencial das tecnologias digitais, quando mediadas por projetos de conhecimento no desenvolvimento da criatividade em Matemática.

\section{Introdução}

A criatividade faz parte do campo de estudo da Psicologia. "A criatividade em Matemática é vista como a capacidade de apresentar inúmeras possibilidades de solução apropriadas para uma situação-problema [...]" [Gontijo 2006:4].

Segundo Mann (2006), a parte lúdica da matemática foi perdida nas rotinas sistematizadas do cálculo e nas demonstrações. Idris e Nor (2013) constataram em suas pesquisas que os softwares de construções dinâmicas potencializam a criatividade matemática, no ato de animar no plano ou no espaço, um ângulo de triângulo, ou na resolução de um problema usando as ferramentas tecnológicas.

Existe um número significativo de estudos em nível internacional que abordam o tema da criatividade matemática, e.g, os trabalhos de Balka (1974), Dunn (1975) e Haylock (1984), que tratam do assunto a partir da perspectiva da avaliação do fenômeno. Este artigo descreve uma experiência didática com um grupo 36 de alunos de nono ano de uma escola municipal no município de Imperatriz-MA, cujo objetivo foi 
V Congresso Brasileiro de Informática na Educação (CBIE 2016)

Anais do XXII Workshop de Informática na Escola (WIE 2016)

analisar o uso das tecnologias digitais no desenvolvimento da criatividade em matemática mediada por um projeto de conhecimento.

\section{Os Projetos de Conhecimento como Estratégia de Ensino e Aprendizagem}

A escolha da metodologia por projetos de conhecimento justifica-se pela necessidade de envolver os alunos em atividades de construção, que envolve o pensar, o agir e a reflexão construtiva [Paulinho Filho, Nuñes e Ramalho 2004].

Nessa acepção, acoplou-se seletivamente: uma ferramenta de construção matemática; o GeoGebra, que segundo Hohenwarter e Fuchs (2004) é um programa que permite a construção geométrica de pontos, retas, planos, polígonos, vetores, segmentos, etc., e, ainda visualiza alterações dinâmicas de seus elementos gráficos. Além da metodologia por projetos de conhecimento alinhado às situações-problemas. Então, idealizou-se atividades rumo à criação de uma logomarca, combinando diferentes figuras da geometria plana.

A experiência teve como palco uma Escola de Ensino Fundamental do município de Imperatriz-MA, especificamente, 36 alunos do nono ano A, cuja média de idade era de 13,87 anos. O estudo contou também com colaboração do professor da disciplina (matemático licenciado), um auxiliar de pesquisa (graduado em ciências naturais), uma professora auxiliar (pedagoga), uma supervisora educacional (pedagoga), uma coordenadora pedagógica (historiadora), um mestre em história da arte, um técnico em laboratório de informática (LABINF), um especialista em Linux e o professor pesquisador.

A intervenção durou um semestre escolar, com início em agosto e término em dezembro de 2015, com uma frequência semanal. A turma foi dividida (em comum acordo) em dois grupos de 18 alunos, distribuídos em nove computadores. Os encontros tinham uma dinâmica de tal sorte que o pesquisador e professor da disciplina se encontravam nas segundas-feiras e com os alunos nas quintas-feiras.

Os registros das atividades desenvolvidas durante a realização do estudo foram capturados de diferentes maneiras: em expressão fotográfica (fotos e vídeos) através de câmeras de celulares; pelas marcas da trajetória dos alunos no exercício das suas atividades, por meio dos protocolos de construção do GeoGebra; nos relatórios de campo, naquilo que o pesquisador percebeu, ouviu, viu, experimentou e pensou. A pesquisa foi autorizada pela Secretaria Municipal de Educação (SEMED), pelos pais ou responsáveis dos alunos, pelos próprios alunos e a Coordenação Pedagógica.

O estudo foi apoiado pela pesquisa quanto-qualitativa. A abordagem respondeu as demandas do projeto de conhecimentos à luz das situações-problemas, no sentido de analisar a criatividade matemática. Fez-se uso também da pesquisa-ação, alinhada à pesquisa participativa que, segundo Engel (2000) caracteriza-se pela inserção ativa no ambiente do pesquisado, no sentido de conhecer vivências e saberes tácitos rumo à superação da lacuna entre teoria e prática. 
V Congresso Brasileiro de Informática na Educação (CBIE 2016)

Anais do XXII Workshop de Informática na Escola (WIE 2016)

\section{Produção Criativa: respostas dos alunos à criação de uma logomarca}

As produções criativas dos grupos que participaram da intervenção didática produziram 35 diferentes logomarcas. As análises a seguir recaem sobre as produções que apresentaram maior nível de criatividade, segundo o julgamento de uma banca avaliadora. A Figura 1 a seguir mostra essas escolhas.

(1)

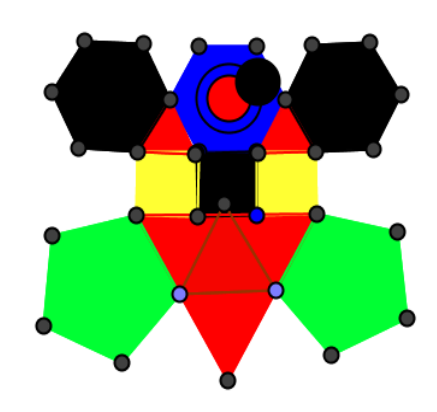

(2)

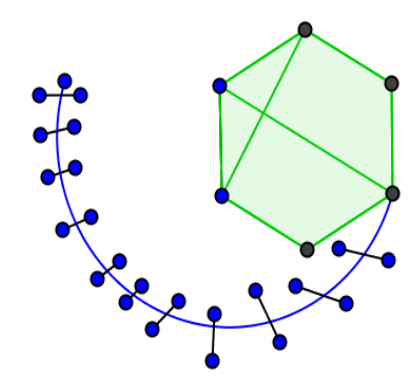

(3)

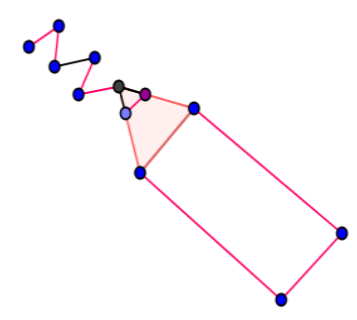

Figura 1. Destaque entre as logomarcas

A seguir mostra-se um recorte dos resultados da produção total das díades, segundo a produção individual dos alunos, nos aspectos da fluência, flexibilidade e originalidade. A avaliação levou em consideração:

Fluência: número de construções produzidas a partir da combinação das figuras geométricas planas - pontos, retas, segmentos de retas, polígonos, etc., (peso um para cada construção).

Flexibilidade: número de categorias de construções produzidas usando mais de três figuras geométrica plana (peso um para cada construção).

Originalidade: respostas raras que teve como parâmetro de julgamento os preceitos de Lubart (2007). A equipe de apoio pedagógico julgou os trabalhos dos alunos em relação aos parâmetros de pouco criativos (associado aos pesos 1 e 2 ); medianamente criativos (associados aos pesos 3, 4 e 5) e altamente criativos (associados aos pesos 6 e 7), então atribuiu-se peso um somente para as construções medianamente e altamente criativa.

Ao final da experiência, a maioria absoluta conseguiu realizar suas atividades e operar satisfatoriamente com a ferramenta de construção dinâmica e com os aplicativos de produtividade, além de fazer uso do computador convencional. $\mathrm{O}$ desafio proposto no projeto levou os alunos a manipular formas geométricas, com ajuda do GeoGebra. Em $\{(1)$ o besouro) $\}$, usou hexágonos regulares, pentágonos, círculos e circunferências, pontos, quadrados e triângulos equiláteros. Nota-se que, a ação inicial mediada por um desafio, levou à construção de algo novo pela associação com outras formas, naquilo que Lubart (2007) discorre sobre a capacidade de juntar elementos para formar uma nova ideia.

O desenho (3), apresenta um singelo lápis construído a partir da combinação de um retângulo, um triângulo, alguns pontos, ângulos e vários segmentos de retas. $\mathrm{O}$ desenho mostra um lápis ativo escrevendo a primeira letra do nome da turma (Mary + 
Ray_+), em homenagem às pessoas desse grupo. Essa construção é um apelo a uma pedagogia ativa em oposição ao ensino repetitivo-passivo.

A criação (2) faz um apelo ao lúdico e ao imaginário infantil, então combinam pontos, segmentos de retas, arco e circunferência, ângulos, triângulos e quadriláteros para fazer uma bela pipa. Não tem como precisar quanto desses experimentos impactaram as estruturas cognitivas, entretanto Idris e Nor (2010), Vieira e Baptista (2015) e Shimohara e Sobreira (2015) encontraram indícios em suas pesquisas, que em ambientes tecnológicos, os alunos são levados a refletir sobre as implicações matemáticas de suas ações. Ações e reflexões são a faísca e motor da construção do conhecimento, segundo os fundamentos da epistemologia genética. Consoante Piaget (1995), a fonte de novidades está na necessidade de um equilíbrio entre o jogo da assimilação e acomodação no eterno devir da busca.

\section{Avaliação da Experiência Didática: o Teste de Criatividade em Matemática (TCM)}

O TCM avalia a criatividade matemática nas habilidades da fluência, flexibilidade e originalidade, nos aspectos da elaboração e resolução de problemas. Na sistematização desse instrumento, Gontijo (2009) levou em consideração uma pesquisa exploratória junto aos alunos de um curso de licenciatura em Matemática e alunos do ensino médio provenientes de escolas públicas e particulares, que observou aspectos relativos à complexidade, variedade das respostas alinhadas às situações-problemas e principalmente da não exigência de conhecimentos matemáticos específicos em sua resolução.

Os resultados mostram que, houve um aumento significativo na criatividade em Matemática do grupo de alunos que participaram da experiência didática, que cresceu em média 45,80\%. Ou seja, o grupo variou de 131 para 191 em sua produtividade criativa, nos aspecto da resolução e elaboração de problemas. Além desse fato, observase também um aumento no aproveitamento dos alunos no TCM, em média 17,7\% $(79,4 \%$ - 61,7\%). Nota-se que, o grupo melhorou em relação a ele mesmo, segundo os resultados dos pré e pós-testes de criatividade em Matemática.

\section{Implicações do Estudo e Conclusões}

Apesar dos resultados mostrarem um incremento da criatividade em matemática do grupo que participou da experiência didática, não há como precisar o quanto se deve exclusivamente às Tecnologias Digitais de Informação e Comunicação (TDIC), às oficinas de arte, ao projeto de conhecimento e as estratégias de resolução de problemas. Além disso, existem outros fatores alheios à percepção do estudo, tais como: as vivências e experiências fora do ambiente escolar, que afetam positivamente os resultados dos testes de criatividade em matemática.

Agora, mesmo com tais implicações, o estudo colabora com educação matemática ao criar alternativas diferentes às já consagradas técnicas de transmissão do conhecimento. Os resultados mostraram a importância do uso das TDIC acoplados aos projetos de conhecimento para promover a criatividade em Matemática. Idris e Nor (2010) indicam em suas pesquisas a importância da criatividade na construção do conhecimento matemático, então, é possível aplacar o problema do rendimento dos alunos em Matemática, com programas para desenvolver o fenômeno criativo. 
V Congresso Brasileiro de Informática na Educação (CBIE 2016)

Anais do XXII Workshop de Informática na Escola (WIE 2016)

As tecnologias digitais exercem grande fascínio com o público jovem, entretanto o estudo mostrou que, a maioria dos alunos envolvidos na pesquisa possuía grandes dificuldades com os computadores de mesa e os programas de produtividade do Linux. Suas experiências com os aplicativos, os celulares e os jogos on-line, não lhes renderam vantagens com os equipamentos do LABINF. Esse fato mostra a importância dos projetos para mediar o conhecimentoadquirido nas experiências pessoais e informais. Os resultados indicam que, as tecnologias digitais mediados pelos projetos de conhecimento, concorrem para o desenvolvimento da criatividade em Matemática.

\section{Referências}

Balka, D. S. (1974). "Creative Ability in Mathematics". Arithmetic Teacher, 21(7), 633636.

Dunn, J. A. (1975). "Tests of creativity in mathematics". International Journal of Mathematical Education in Science and Technology, 6(3), 327-332.

Engel, G. I. (2000). “Pesquisa-ação”. Educar em Revista, (16), 181-191.

Gontijo, C. H. (2006). "Resolução e Formulação de Problemas: caminhos para o desenvolvimento da criatividade em Matemática". InAnais do Simpósio Internacional de Pesquisa em Educação Matemática, Brasil, 2, 1-11.

Gontijo, C. H. (2009). Relações entre criatividade, criatividade em matemática e motivação em matemática de alunos do ensino médio.Tese de doutoramento nãopublicada, Universidade de Brasília, Brasília, Brasil.

Haylock, D. W. (1984). Aspects of mathematical creativity in children aged 11-12. Unpublished doctoral dissertation, University of London, London, 1984.

Idris, N. e Nor, N. M. (2010). "Mathematical creativity: usage of technology". Procedia-Social andBehavioralSciences,2(2), 1963-1967.

Lubart, T. (2007). Psicologia da criatividade. Porto Alegre: Artmed.

Mann, E. L. (2006). "Creativity: the essence of mathematics". Journal for the Education of the Gifted, 30(2), 236-260.

Paulinho Filho, J., Nuñez, I. B. e Ramalho, B. L. (2004). "Ensino por projetos: uma alternativa para a construção de competência no aluno". In I. B. Nuñeze B. L. Ramalho. Fundamentos do ensinoaprendizagem das Ciências Naturais e da Matemática: o novo Ensino Médio(pp. 265-283). Porto Alegre: Sulina.

Piaget, J. (1995).Abstração reflexionante:relações lógico-aritméticas e ordem das relações espaciais. Porto Alegre: Artes Médicas.

Shimohara, C. e Sobreira, E. (2015).“Criando jogos digitais para a aprendizagem de matemática no ensino fundamental I'. InAnais do Workshop de Informática na Escola, Brasil, 1, 72-81.

Vieira, M. e Baptista, B. (2015). “A utilização das Tecnologias da Informação e Comunicação nos projetos educacionais interdisciplinares". InAnais do Workshop de Informática na Escola, Brasil, 1, 197-206. 